\title{
Satisfaction with care of hospitalised patients with advanced cancer in the Netherlands
}

Cancer patients' satisfaction with hospital care

Marijanne Engel, MSc; Arianne Brinkman-Stoppelenburg, MSc; Daan Nieboer, MSc; Agnes van der Heide MD, PhD

\section{Authors}

Marijanne Engel, MSc, PhD student, Erasmus Medical Center Rotterdam, Department of Public Health, Rotterdam, the Netherlands

Arianne Brinkman-Stoppelenburg, MSc, Researcher, Erasmus Medical Center Rotterdam, Department of Public Health, Rotterdam, the Netherlands

Daan Nieboer, MSc, Statistician, Erasmus Medical Center Rotterdam, Department of Public Health, Rotterdam, the Netherlands

Agnes van der Heide, MD, PhD, Professor, Erasmus Medical Center Rotterdam, Department of Public Health, Rotterdam, the Netherlands

\section{Corresponding author}

Marijanne Engel, MSc, PhD student, Erasmus Medical Center Rotterdam, Department of Public Health, Wytemaweg 80, 3015 CN Rotterdam, the Netherlands (email: m.engel@erasmusmc.nl)

\section{Acknowledgement}

This study is funded by ZonMw, the Netherlands Organisation for Health Research and Development (grant number 11510031), and the Erasmus Medical Center MRACE (grant number 2011-11112), Rotterdam, the Netherlands.

We are most grateful to all patients who kindly agreed to participate in the study and we thank physicians, nurses and other care providers from the participating hospitals for their help in collecting data.

\section{Conflict of interest statement}

All authors declare that they have no competing interests. The study was conducted independent from the funders. All authors have full access to all the data (including statistical reports and tables) in the study and take responsibility for the integrity of the data and the accuracy of the analysis. 


\section{Satisfaction with care of hospitalised patients with advanced cancer in the Netherlands}

\section{Abstract}

Objective: We aimed to assess the level of satisfaction with hospital care of patients with advanced cancer and its association with quality of life and other patient characteristics.

Methods: Eligible patients were asked to fill out the EORTC INPATSAT-32 questionnaire, measuring patient satisfaction, and the EORTC QLQ-C15-PAL, measuring quality of life. Factor analysis was performed to identify underlying patterns in satisfaction. Multivariable regression analyses were used to assess associations of quality of life and other patient characteristics with satisfaction.

Results: 105 patients participated in the study. The mean general satisfaction score was 72 (sd 21). Factor analysis identified three underlying dimensions: satisfaction with nurses (explaining 62,1\% of the total variance), satisfaction with physicians $(7,7 \%)$ and satisfaction with hospital services $(5,3 \%)$. Associations were found between global health and general satisfaction $(\beta=0.35, p=0.01)$, and between emotional functioning and satisfaction with hospital services $(\beta=0.016, p<0.01)$. Further, diagnosis of breast cancer was associated with satisfaction with physicians $(\beta=1.06, p<0.01)$, and dyspnoea with satisfaction with hospital services $(\beta=0.007, p=0.03)$.

Conclusions: Patients with advanced cancer are reasonably satisfied with hospital care. The INPATSAT-32 mainly measures satisfaction with nurses. Satisfaction with care and quality of life seem to represent distinct outcomes of hospital care in patients with advanced cancer.

Keywords: patient satisfaction; palliative care; quality of life; neoplasms; hospitals; cross-sectional studies 


\section{Introduction}

Patient satisfaction is an important outcome of patient-centered care, which is considered to be one of the key characteristics of high-quality care (de Boer, Delnoij, \& Rademakers, 2013; Dy, Shugarman, Lorenz, Mularski, \& Lynn, 2008; Plotti et al., 2015). Therefore, patient satisfaction is an essential aspect of measuring quality of care (Bredart et al., 2005; Wentlandt et al., 2016). Patient satisfaction can be described as the extent to which patients' health care experiences match with the level and quality of care they expect (Bredart et al., 2005; Kullberg, Sharp, Johansson, \& Bergenmar, 2015). Patients have different backgrounds, experiences and expectations from their care. Patient satisfaction is highly dependent on such factors and may not always be associated with quality of care (Aiken et al., 2012; Bredart et al., 2005; Buda et al., 2013; Suhonen et al., 2018; Vedel et al., 2014). The key aspects to measure may differ according to the patient's disease, the care setting, and the type of intervention (Dy et al., 2008). When measured adequately, patient satisfaction scores are supposed to provide a robust measure of quality of care (Manary, Boulding, Staelin, \& Glickman, 2013).

Patient satisfaction with end-of-life care refers to all relevant processes associated with health care delivery for patients with advanced illness (Bredart et al., 2005; Buda et al., 2013). To be useful, measurement of satisfaction with end-of-life care should address aspects that are important to patients and should be responsive to improvements in healthcare delivery (Dy et al., 2008). Patient satisfaction with end-of-life care is a complex concept that is not easily distinguished from related concepts, such as quality of life and quality of dying (Dy et al., 2008; Wentlandt et al., 2016).

Cancer is one of the most common causes of death. End-of-life care therefore often concerns patients with cancer. In 2014, almost 43,000 persons died of cancer in the Netherlands, which represents $31 \%$ of the total number of deceased people in that year (RIVM (the National Institute for Public Health and the Environment), 2016). Bekelman et al. (2016) found that in the Netherlands 77\% of cancer patients were admitted to an acute care hospital in the last 180 days of life, which percentage is low compared to other European countries. In the last 30 days of life, the Netherlands has the lowest rate of hospitalisations (44\%) (Bekelman et al., 2016). Ko et al. (2014) found that 17\% of Dutch patients with advanced cancer were admitted to hospital in the last week of life and died there.

Patient satisfaction with hospital care reflects the perception of the patient of the quality of care they receive during their hospitalisation (Kullberg et al., 2015; Wentlandt et al., 2016). Most research on patient satisfaction with end-of-life care in the hospital has been conducted in specific settings, such as a palliative care unit or an oncology department (Arora et al., 2010; Bredart et al., 2009; Buzgova, Hajnova, Sikorova, \& Jarosova, 2014; Dy et al., 2008; Nguyen et al., 2014; Seccareccia et al., 2015; Wentlandt et al., 2016) or in patients with a specific type of cancer, such as gynaecologic cancer or lung cancer (Plotti et al., 2015; Pompili et al., 2013; Skret-Magierlo, Ras, Barnas, \& Skret, 2016). Little is known about satisfaction with in-hospital care of patients with advanced cancer.

The aim of this study was to explore satisfaction with hospital care of patients with advanced cancer, to study the underlying dimensions of satisfaction, and to explore the relation of satisfaction with patients' demographics, disease characteristics and quality of life. 


\section{Methods}

\section{Study design}

This cross-sectional study was part of the COMPASS study, a multicentre study on the effects and costs of consultation of expert teams for palliative care in hospitals in the Netherlands (BrinkmanStoppelenburg, Polinder, Vergouwe, \& van der Heide, 2015). The study was performed in nine hospitals, both university and general hospitals.

\section{Patients and data collection}

Patients were recruited for the study in the period January 2013 - February 2015. Inclusion criteria were: admission to the hospital with advanced cancer, age 18 years or older, and the attending physician answering "no" to the Surprise Question: "Would you be surprised if this patient would die in the next year?" (Moss et al., 2010). Eligible patients were identified by the attending physician; they received an information letter about the study and were informed by the attending nurse.

\section{Questionnaires}

After obtaining written informed consent, patients were invited to fill in the European Organisation for Research and Treatment of Cancer (EORTC) IN-PATient SATisfaction 32 (items) questionnaire (INPATSAT-32) and the EORTC Quality of Life Questionnaire Core 15 (items) Palliative care (QLQ-C15 $\mathrm{PAL}$ ), on the $14^{\text {th }}$ day after inclusion. The attending physician was asked to fill in a questionnaire about the patient's diagnosis, performance status, comorbidities and life expectancy.

\section{Satisfaction With Care (EORTC INPATSAT-32)}

The EORTC developed the INPATSAT-32 questionnaire to assess satisfaction with hospital care of cancer patients. The INPATSAT-32 consists of 32 items assessing patients' appraisal of the quality of hospital physicians (eleven items) and nurses (eleven items), as well as aspects of the organisation of care and hospital environment (nine items), and general satisfaction (one item) (Bredart et al., 2005; Plotti et al., 2015). The INPATSAT-32 was conceptualised as having 11 multi-item scales and three single-item scales (Table 2) and uses a five-point response scale, from 'poor' to 'excellent'. The INPATSAT-32 has been validated and tested in a large, international sample of patients with cancer. The INPATSAT-32 has demonstrated excellent convergent validity and internal consistency, and high reliability (Bredart et al., 2005). The INPATSAT-32 general satisfaction single-item scale was the primary outcome measure in our study.

Quality of Life (EORTC QLQ-C15-PAL)

Quality of life measurement focuses on patient outcomes in the physical, psychological and the social domain (Aboshaiqah et al., 2016; Zimmermann et al., 2014). The EORTC QLQ-C15-PAL questionnaire measures quality of life in palliative care and is an abbreviated 15-item version of the EORTC QLQC30. The QLQ-C15-PAL consists of 15 questions: two multi-item functional scales (emotional and physical functioning), two multi-item symptom scales (fatigue, pain), five single-item symptom scales (nausea and vomiting, dyspnoea, insomnia, appetite loss, constipation), and one final question referring to overall quality of life (global health status) (Table 1). It uses a four-point response scale from 1 (not at all) to 4 (very much), with the exception of health status which was rated from 1 (very poor) to 7 (excellent) (Groenvold et al., 2006). The QLQ-C15-PAL has been demonstrated to have a 
good content validity as a "core palliative care questionnaire" that assesses common symptoms and problems of patients with advanced disease (Groenvold et al., 2006).

\section{Statistical analyses}

Scores of the EORTC INPATSAT-32 for items within a scale were summed and divided by the number of items in the scale. Multi-item as well as single-item scale scores were then linearly transformed to scores ranging from 0 to 100, with a higher score representing a higher level of satisfaction.

The EORTC scoring manual was used to generate the QLQ-C15-PAL scores (Groenvold et al., 2006). Scores range from 0 to 100 . A higher score on global health, the emotional functioning scale or the physical functioning scale, indicates better global health or better functioning. Inversely, a higher score on a symptom indicates more severe symptoms or problems.

In order to explore underlying dimensions of satisfaction as measured with the INPATSAT-32 we looked for latent factors with an exploratory factor analysis (EFA) with principal axis factoring (Pett, Lackey, \& Sullivan, 2003; Taherdoost, Sahibuddin, \& Jalaliyoon, 2014; Yong \& Pearce, 2013). Direct Oblimin was used to rotate variables with the aim to find a structure with distinct factors, in which every factor includes related items with loadings as high as possible. General satisfaction and the resulting factors were used as outcomes in univariate and multivariable regression models. We performed univariate analysis to assess the association of patient characteristics with satisfaction scores, where $p<0.30$ was considered statistically significant. We subsequently performed multivariable regression analysis with variables that were significantly associated with satisfaction in the univariate analysis. All p-values were two-sided. Data were analysed using the statistical program SPSS version 24 . 


\section{Results}

\section{Patient characteristics}

One hundred and five patients participated in our study. Fifty four percent of the participants were female. Patients' mean age was 67 (sd 10). Most patients (43\%) had no comorbidities, $30 \%$ had a life expectancy of less than three months. Place of residence of most (96\%) patients was their own home. The median duration of hospital admission was nine days (range 1-50). Most hospital admissions were unplanned (85\%) (Table 1).

Patients' mean global health score was 59 (sd 19). The mean score for emotional functioning was 77 (sd 23) and for physical functioning it was 41 (sd 28). As for symptoms, patients scored on average highest (worst) on fatigue, with a mean score of 58 (sd 27), and appetite loss, with a mean score of 40 (sd 33) (Table 1).

\section{Satisfaction with hospital care}

The mean score for general satisfaction with hospital care was 72 (sd 21). Satisfaction was highest for nurses' technical skills (72, sd 21) and nurses' interpersonal skills (71, sd 23) Satisfaction was lowest for access to the hospital (parking facilities, transport options to the hospital) (59, sd 22) and 'other hospital personnel' (60, sd 21) (Table 2).

Principal axis factoring yielded three components with eigenvalues exceeding 1, which explained 62,1 $\%, 7,7 \%$ and $5,3 \%$ of the total variance, respectively (Table 2 ). After Oblimin rotation the pattern matrix showed three factors, representing 'satisfaction with nurses and exchange of information', 'satisfaction with physicians', and 'satisfaction with hospital services' (Table 2).

\section{Associations between patient characteristics and satisfaction with hospital care}

Based on significant univariate associations, patients' age, comorbidity, whether or not the hospital admission was planned, WHO performance status, palliative care team consultation, type of hospital, global health, physical functioning, emotional functioning, fatigue, pain, dyspnoea and appetite loss were included in the multivariable analysis to assess determinants of patients' general satisfaction with care (Table 3). Likewise, place of residence, comorbidity, palliative care team consultation, global health, emotional functioning, pain and constipation were included in the multivariable analysis to assess determinants of satisfaction with nurses and exchange of information (Table 4). Age, diagnosis, comorbidity, type of hospital, global health, physical functioning, emotional functioning, fatigue, pain, appetite loss and constipation were included in the multivariable analysis to assess determinants of satisfaction with physicians (Table 5). Finally, patients' gender, WHO performance status, palliative care team consultation, type of hospital, global health, emotional functioning, fatigue, nausea and vomiting, pain, dyspnoea and appetite loss were included in the multivariable analysis to assess determinants of satisfaction with hospital services (Table 6).

The analyses showed that patient demographics and disease characteristics were not associated with patients' general satisfaction or its underlying dimensions, except for a diagnosis of breast cancer, which was associated with patients' satisfaction with physicians $(\beta=1.06, p<0.01)$ (Table 3-6). Further, we found that better global health was associated with higher general satisfaction $(\beta=0.35, p=0.01)$, and that better emotional functioning $(\beta=0.016, p<0.01)$ and more severe dyspnoea $(\beta=0.007$, $p=0.03$ ) were associated with higher satisfaction with hospital services. 
Global health and other dimensions of quality of life were not associated with satisfaction with nurses and exchange of information or satisfaction with physicians. 


\section{Discussion}

We found that patients with advanced cancer were reasonably satisfied with the care they received during their admission to the hospital: the mean score on general satisfaction was 72 . Satisfaction was highest for nurses' technical and interpersonal skills and lowest for access to the hospital and other hospital personnel. Factor analysis yielded three underlying dimensions: satisfaction with nurses and exchange of information, satisfaction with physicians, and satisfaction with hospital services. We found that the INPATSAT-32 mainly measures satisfaction with nurses and exchange of information.

The satisfaction scores in this study overall seem to be in accordance with scores found in other studies in patients with cancer (Arora et al., 2010; Bredart et al., 2013; Nguyen et al., 2014; SkretMagierlo et al., 2016). Bredart et al. (2013) found scores ranging from 61 (physicians' availability) to 78 (nurses' interpersonal skills) among breast cancer patients (19\% of the respondents had a metastatic stage), and Skret-Magierlo et al. (2016) found highest scores on technical skills of physicians (70) and nurses (67), and the worst score on access to the hospital (51) among patients with endometrial cancer. The dimensions we found as explaining a large part of the variance in satisfaction scores, nursing care and physician care, were confirmed in other studies to represent the most relevant dimensions of satisfaction (Bredart et al., 2009; Plotti et al., 2015). Plotti et al. (2015) found that expert care for patients with gynaecological cancer was associated with significant higher scores on satisfaction with physicians' information provision, nurses' technical skills, nurses' information provision, and general satisfaction than standard care. Bredart et al. (2009) found that specialised care for patients with different types of cancer was associated with significant higher scores on satisfaction with nurses' availability than standard care.

Other studies explored the important and complex role of nurses in cancer care and patient satisfaction (Kullberg, Sharp, Johansson, Brandberg, \& Bergenmar, 2017; Suhonen et al., 2018; Walczak et al., 2017). These studies described or implemented specific nursing interventions that are assumed to improve cancer patients' satisfaction with care. Kullberg et al. (2017) found that, after implementing a specific nurse handover procedure in an oncological inpatient setting, patients from the intervention ward scored higher on satisfaction with exchange of information between the caregivers compared to patients from the control wards. Suhonen et al. (2018) described differences between European countries in hospitalised cancer patients' perceptions of individualised nursing care that is assumed to improve patient satisfaction and other outcomes. Patients' perceptions of individuality and differences between countries in this study (Suhonen et al., 2018) illustrate the complexity of the development of nursing care that responds to the variety of needs of cancer patients. Walczak et al. (2017) evaluated the efficacy of a nurse-facilitated communication program for patients with advanced cancer to improve end-of-life care and found that patient satisfaction with this program in the intervention group was high.

Association of patient demographics and disease characteristics with satisfaction In multivariable analyses, we found no significant associations between patient demographics and satisfaction with hospital care. In other studies, older patients with cancer were found to be more satisfied than younger patients (Hannon et al., 2013; Nguyen et al., 2014). In univariate analysis, we also found a positive association between age and general satisfaction, and between age and satisfaction with physicians. 
Multivariable analysis showed a positive association between having a diagnosis of breast cancer and satisfaction with physicians. One explanation can be that the five-year survival of patients with breast cancer is high as compared to other types of cancer (RIVM (the National Institute for Public Health and the Environment), 2016). Nguyen et al. (2014) found that patients treated for head and neck cancer were less satisfied with physicians' provision of information, and hospital environment as compared to those treated for prostate cancer. Hannon et al. (2013) found no association between different types of cancer and patient satisfaction with end-of-life care.

\section{Association of quality of life with satisfaction}

Quality of life was to a limited extent associated with satisfaction. Global health was positively associated with general satisfaction, but not with any of the underlying dimensions of satisfaction. Emotional functioning and dyspnoea were associated with satisfaction with hospital services. In the literature, better global health (Nguyen et al., 2014; Scarpa et al., 2013) has been reported to be associated with higher satisfaction scores with hospital care too. Nguyen et al. (2014) found that a decrease of global health in cancer patients, during and after treatment, led to a decrease in satisfaction scores, mainly in the evaluation of physicians. Aboshaiqah et al. (2016) found that better emotional functioning was associated with higher general satisfaction with hospital care.

With regard to symptoms, a study in patients with gynaecological malignancies showed no association between symptom severity and satisfaction with treatment (von Gruenigen et al., 2006). Vedel et al. (2014) found that for patients in palliative care it was important they could discuss symptoms with physicians or nurses, regardless of whether symptoms were relieved or not.

The question has been raised if scores on (dimensions of) quality of life and general satisfaction represent the same general feeling of 'happiness', which is easily influenced by factors unrelated to quality of care (Manary et al., 2013; Wentlandt et al., 2016). In our study, dimensions of quality of life were to a limited extent associated with satisfaction, which suggests that patients' satisfaction with end-of-life care reflects a dimension of quality of care that only partly overlaps with quality of life.

This study has several strengths: it was conducted in nine hospitals in the Netherlands, both university and general hospitals. All patients had a primary diagnosis of cancer, but there was a variation in types of cancer, number of comorbidities and treatment status. Besides the variation in demographics and disease characteristics, all patients had advanced cancer with a limited prognosis of less than a year.

A limitation is the total number of 105 patients. Although the recruitment rate was low, the size of the sample was consistent with comparable studies. Another limitation is that for each patient quality of life and patient satisfaction were measured on the same day (on the $14^{\text {th }}$ day after inclusion). Drawing robust causal inferences is therefore not possible.

\section{Conclusion}

Understanding which patient demographics, disease characteristics and dimensions of quality of life are related with satisfaction with hospital care in patients with advanced cancer is important for guiding improvement in hospital care. We found that patients with advanced cancer in the Netherlands are reasonably satisfied with hospital care. Satisfaction with hospital care in patients with advanced cancer as measured with the INPATSAT-32 mainly represents satisfaction with nurses 
and exchange of information. Global health was the only dimension of quality of life that was associated with general satisfaction. The underlying dimensions satisfaction with nurses and satisfaction with physicians, represent aspects of quality of care distinct from dimensions of quality of life. Since nursing care and exchange of information seem to be the main underlying dimension of patient satisfaction, our findings may help to develop recommendations to address the needs of hospitalised patients with advanced cancer and improve end-of-life care. 


\section{References}

Aboshaiqah, A., Al-Saedi, T. S., Abu-Al-Ruyhaylah, M. M., Aloufi, A. A., Alharbi, M. O., Al-Saedi, A. S., \& Al-Erwi, A. F. (2016). Quality of life and satisfaction with care among palliative cancer patients in Saudi Arabia. Palliat Support Care, 14(6), 621-627. doi:10.1017/s1478951516000432

Aiken, L. H., Sermeus, W., Van den Heede, K., Sloane, D. M., Busse, R., McKee, M., . . Kutney-Lee, A. (2012). Patient safety, satisfaction, and quality of hospital care: cross sectional surveys of nurses and patients in 12 countries in Europe and the United States. BMJ, 344, e1717. doi:10.1136/bmj.e1717

Arora, V., Philp, S., Nattress, K., Pather, S., Dalrymple, C., Atkinson, K., . . Carter, J. (2010). Patient satisfaction with inpatient care provided by the Sydney Gynecological Oncology Group. Patient Relat Outcome Meas, 1, 179-184. doi:10.2147/PROM.S13897

Bekelman, J. E., Halpern, S. D., Blankart, C. R., Bynum, J. P., Cohen, J., Fowler, R., . . International Consortium for End-of-Life, R. (2016). Comparison of Site of Death, Health Care Utilization, and Hospital Expenditures for Patients Dying With Cancer in 7 Developed Countries. JAMA, 315(3), 272-283. doi:10.1001/jama.2015.18603

Bredart, A., Bottomley, A., Blazeby, J. M., Conroy, T., Coens, C., D'Haese, S., . . Aaronson, N. K. (2005). An international prospective study of the EORTC cancer in-patient satisfaction with care measure (EORTC IN-PATSAT32). Eur J Cancer, 41(14), 2120-2131. doi:10.1016/j.ejca.2005.04.041

Bredart, A., Dolbeault, S., Savignoni, A., Simard, S., Gomme, S., Asselain, B., \& Copel, L. (2009). Pilot evaluation of a French interdisciplinary supportive care department. Support Care Cancer, 17(12), 1507-1516. doi:10.1007/s00520-009-0617-3

Bredart, A., Kop, J. L., Griesser, A. C., Fiszer, C., Zaman, K., Panes-Ruedin, B., . . Dolbeault, S. (2013). Assessment of needs, health-related quality of life, and satisfaction with care in breast cancer patients to better target supportive care. Ann Oncol, 24(8), 2151-2158. doi:10.1093/annonc/mdt128

Brinkman-Stoppelenburg, A., Polinder, S., Vergouwe, Y., \& van der Heide, A. (2015). Palliative care consultation services in hospitals in the Netherlands: the design of the COMPASS study. BMC Palliat Care, 14, 68. doi:10.1186/s12904-015-0069-0

Buda, A., Cuzzocrea, M., Montanelli, L., Passoni, P., Bargossi, L., Baldo, R., . . Milani, R. (2013). Evaluation of Patient Satisfaction Using the EORTC IN-PATSAT32 Questionnaire and Surgical Outcome in Single-Port Surgery for Benign Adnexal Disease: Observational Comparison with Traditional Laparoscopy. Diagn Ther Endosc, 2013, 578392. doi:10.1155/2013/578392

Buzgova, R., Hajnova, E., Sikorova, L., \& Jarosova, D. (2014). Association between unmet needs and quality of life in hospitalised cancer patients no longer receiving anti-cancer treatment. Eur J Cancer Care (Engl), 23(5), 685-694. doi:10.1111/ecc.12181

de Boer, D., Delnoij, D., \& Rademakers, J. (2013). The importance of patient-centered care for various patient groups. Patient Educ Couns, 90(3), 405-410. doi:10.1016/j.pec.2011.10.002

Dy, S. M., Shugarman, L. R., Lorenz, K. A., Mularski, R. A., \& Lynn, J. (2008). A systematic review of satisfaction with care at the end of life. J Am Geriatr Soc, 56(1), 124-129. doi:10.1111/j.15325415.2007.01507.x

Groenvold, M., Petersen, M. A., Aaronson, N. K., Arraras, J. I., Blazeby, J. M., Bottomley, A., . . . Bjorner, J. B. (2006). The development of the EORTC QLQ-C15-PAL: a shortened questionnaire for cancer patients in palliative care. Eur J Cancer, 42(1), 55-64. doi:10.1016/j.ejca.2005.06.022

Hannon, B., Swami, N., Krzyzanowska, M. K., Leighl, N., Rodin, G., Le, L. W., \& Zimmermann, C. (2013). Satisfaction with oncology care among patients with advanced cancer and their caregivers. Qual Life Res, 22(9), 2341-2349. doi:10.1007/s11136-013-0371-3 
Ko, W., Deliens, L., Miccinesi, G., Giusti, F., Moreels, S., Donker, G. A., . . . Van den Block, L. (2014). Care provided and care setting transitions in the last three months of life of cancer patients: a nationwide monitoring study in four European countries. BMC Cancer, 14, 960. doi:10.1186/1471-2407-14-960

Kullberg, A., Sharp, L., Johansson, H., \& Bergenmar, M. (2015). Information exchange in oncological inpatient care--patient satisfaction, participation, and safety. Eur J Oncol Nurs, 19(2), 142147. doi:10.1016/j.ejon.2014.10.005

Kullberg, A., Sharp, L., Johansson, H., Brandberg, Y., \& Bergenmar, M. (2017). Patient satisfaction after implementation of person-centred handover in oncological inpatient care - A crosssectional study. PLoS One, 12(4), e0175397. doi:10.1371/journal.pone.0175397

Manary, M. P., Boulding, W., Staelin, R., \& Glickman, S. W. (2013). The patient experience and health outcomes. N Engl J Med, 368(3), 201-203. doi:10.1056/NEJMp1211775

Moss, A. H., Lunney, J. R., Culp, S., Auber, M., Kurian, S., Rogers, J., . . Abraham, J. (2010). Prognostic significance of the "surprise" question in cancer patients. J Palliat Med, 13(7), 837-840. doi:10.1089/jpm.2010.0018

Nguyen, T. V., Anota, A., Bredart, A., Monnier, A., Bosset, J. F., \& Mercier, M. (2014). A longitudinal analysis of patient satisfaction with care and quality of life in ambulatory oncology based on the OUT-PATSAT35 questionnaire. BMC Cancer, 14, 42. doi:10.1186/1471-2407-14-42

Pett, M., Lackey, N., \& Sullivan, J. (2003). Making Sense of Factor Analysis. Thousand Oaks, CA: SAGE Publications, Inc.

Plotti, F., Capriglione, S., Miranda, A., Scaletta, G., Aloisi, A., Luvero, D., . . Angioli, R. (2015). The impact of gynecologic oncology training in the management of cancer patients: is it really necessary? A prospective cohort study. Eur J Obstet Gynecol Reprod Biol, 184, 19-23. doi:10.1016/j.ejogrb.2014.11.015

Pompili, C., Brunelli, A., Rocco, G., Salvi, R., Xiume, F., La Rocca, A., . . Martucci, N. (2013). Patient satisfaction after pulmonary resection for lung cancer: a multicenter comparative analysis. Respiration, 85(2), 106-111. doi:10.1159/000337262

RIVM (the National Institute for Public Health and the Environment). (2016). Samenhangend beeld van kanker: ziekte, zorg, mens en maatschappij. Themarapportage van de Staat van Volksgezondheid en Zorg (A coherent picture of cancer: the disease, care, people and society). Retrieved from https://www.rivm.nl/

Scarpa, M., Saadeh, L. M., Fasolo, A., Alfieri, R., Cagol, M., Cavallin, F., . . Castoro, C. (2013). Healthrelated quality of life in patients with oesophageal cancer: analysis at different steps of the treatment pathway. J Gastrointest Surg, 17(3), 421-433. doi:10.1007/s11605-012-2069-1

Seccareccia, D., Wentlandt, K., Kevork, N., Workentin, K., Blacker, S., Gagliese, L., . . Z Zimmermann, C. (2015). Communication and Quality of Care on Palliative Care Units: A Qualitative Study. J Palliat Med, 18(9), 758-764. doi:10.1089/jpm.2014.0408

Skret-Magierlo, J., Ras, R., Barnas, E., \& Skret, A. (2016). Evaluation of the hospital environment for women with endometrial cancer. Ann Agric Environ Med, 23(3), 511-516. doi:10.5604/12321966.1219201

Suhonen, R., Charalambous, A., Berg, A., Katajisto, J., Lemonidou, C., Patiraki, E., . . Radwin, L. E. (2018). Hospitalised cancer patients' perceptions of individualised nursing care in four European countries. Eur J Cancer Care (Engl), 27(1). doi:10.1111/ecc.12525

Taherdoost, H., Sahibuddin, S., \& Jalaliyoon, N. (2014). Exploratory Factor Analysis; Concepts and Theory Advances in Applied and Pure Mathematics, 375-382.

Vedel, I., Ghadi, V., Lapointe, L., Routelous, C., Aegerter, P., \& Guirimand, F. (2014). Patients', family caregivers', and professionals' perspectives on quality of palliative care: a qualitative study. Palliat Med, 28(9), 1128-1138. doi:10.1177/0269216314532154

von Gruenigen, V. E., Hutchins, J. R., Reidy, A. M., Gibbons, H. E., Daly, B. J., Eldermire, E. M., \& Fusco, N. L. (2006). Gynecologic oncology patients' satisfaction and symptom severity during palliative chemotherapy. Health Qual Life Outcomes, 4, 84. doi:10.1186/1477-7525-4-84 
Walczak, A., Butow, P. N., Tattersall, M. H., Davidson, P. M., Young, J., Epstein, R. M., . . Clayton, J. M. (2017). Encouraging early discussion of life expectancy and end-of-life care: A randomised controlled trial of a nurse-led communication support program for patients and caregivers. Int J Nurs Stud, 67, 31-40. doi:10.1016/j.ijnurstu.2016.10.008

Wentlandt, K., Seccareccia, D., Kevork, N., Workentin, K., Blacker, S., Grossman, D., \& Zimmermann, C. (2016). Quality of Care and Satisfaction With Care on Palliative Care Units. J Pain Symptom Manage, 51(2), 184-192. doi:10.1016/j.jpainsymman.2015.10.006

Yong, A. G., \& Pearce, C. (2013). A Beginner's Guide to Factor Analysis: Focusing on Exploratory Factor Analysis. Tutorials in Quantitative Methods for Psychology, 9 (2), 79-94.

Zimmermann, C., Swami, N., Krzyzanowska, M., Hannon, B., Leighl, N., Oza, A., . . Lo, C. (2014). Early palliative care for patients with advanced cancer: a cluster-randomised controlled trial. Lancet, 383(9930), 1721-1730. doi:10.1016/s0140-6736(13)62416-2 
Table 1: Demographics, disease characteristics and quality of life (EORTC QLQ-C15-PAL) of hospitalised patients with advanced cancer $(n=105)$

\begin{tabular}{|c|c|c|}
\hline & & $\begin{array}{c}\text { Total } \\
(\mathrm{n}=105) \\
\mathrm{n}(\%)\end{array}$ \\
\hline \multirow[t]{2}{*}{ Gender } & Female & $57(54)$ \\
\hline & Male & $48(46)$ \\
\hline \multicolumn{2}{|l|}{ Age at admission (mean, sd) } & $67(10)$ \\
\hline \multirow[t]{2}{*}{ Marital status } & Single /unmarried/widowed & $39(37)$ \\
\hline & Married & $66(63)$ \\
\hline \multirow[t]{2}{*}{ Place of residence } & Home & $99(96)$ \\
\hline & Other & $4(4)$ \\
\hline \multirow[t]{3}{*}{ Discharge destination } & Home & $82(83)$ \\
\hline & Nursing home / care home / hospice & $12(12)$ \\
\hline & Other & $5(5)$ \\
\hline \multicolumn{2}{|c|}{ Duration of current hospital admission in days (median, range) } & $9(1-50)$ \\
\hline \multirow[t]{5}{*}{ Diagnosis } & Gastro-intestinal cancer & $44(42)$ \\
\hline & Urogenital cancer & $21(20)$ \\
\hline & Breast cancer & $15(14)$ \\
\hline & Lung cancer & $15(14)$ \\
\hline & Other & $10(10)$ \\
\hline \multirow[t]{3}{*}{ Treatment status } & Patient received anti-tumor therapy & $45(46)$ \\
\hline & No options for anti-tumor therapy left & $35(35)$ \\
\hline & Other & 19 (19) \\
\hline \multirow[t]{3}{*}{ Comorbidity } & No comorbidity & $45(43)$ \\
\hline & 1 comorbidity & $34(32)$ \\
\hline & $>1$ comorbidity & $26(25)$ \\
\hline \multirow[t]{2}{*}{ Hospital admission was } & Planned & $15(15)$ \\
\hline & Unplanned & $88(85)$ \\
\hline \multirow[t]{5}{*}{$\begin{array}{l}\text { WHO performance status. The patient } \\
\text { is.... }\end{array}$} & $\begin{array}{l}\text { (1) Able to carry out all normal } \\
\text { activity without restrictions }\end{array}$ & $7(7)$ \\
\hline & $\begin{array}{l}\text { (2) Restricted in physically strenuous } \\
\text { activity but ambulatory and able to } \\
\text { carry out light work }\end{array}$ & $37(35)$ \\
\hline & $\begin{array}{l}\text { (3) Ambulatory and capable of all } \\
\text { self-care but unable to carry out any } \\
\text { work; up and more than } 50 \% \text { of } \\
\text { waking hours. }\end{array}$ & $29(28)$ \\
\hline & $\begin{array}{l}\text { (4) Capable of only limited self-care; } \\
\text { confined to bed or chair more than } \\
50 \% \text { of waking hours. }\end{array}$ & $28(27)$ \\
\hline & $\begin{array}{l}\text { (5) Completely disabled; cannot carry } \\
\text { on any self-care; totally confined to } \\
\text { bed or chair }\end{array}$ & $4(4)$ \\
\hline \multirow{3}{*}{$\begin{array}{l}\text { Estimated prognosis at admission } \\
\text { according to physician }\end{array}$} & 6-12 months & $34(34)$ \\
\hline & 3-6 months & $35(35)$ \\
\hline & $<3$ months & $30(30)$ \\
\hline \multirow{2}{*}{ Palliative care team consultation } & Yes & $16(15)$ \\
\hline & No & $89(85)$ \\
\hline
\end{tabular}




\begin{tabular}{|ll|c|}
\hline Type of hospital & $\begin{array}{l}\text { University } \\
\text { General }\end{array}$ & $\begin{array}{c}20(19) \\
85(81)\end{array}$ \\
\hline Quality of lifet (mean, sd) & & $\begin{array}{c}\text { Total } \\
(\mathrm{n}=105) \\
\text { Mean (sd) }\end{array}$ \\
\hline Global health status & Global health & $59(19)$ \\
\hline Functional scales & Emotional functioning & $77(23)$ \\
& Physical functioning & $41(28)$ \\
\hline Symptoms & Fatigue & $58(27)$ \\
& Nausea and vomiting & $16(25)$ \\
& Pain & $33(29)$ \\
& Dyspnoea & $28(31)$ \\
Insomnia & $29(29)$ \\
& Appetite loss & $40(33)$ \\
& Constipation & $23(29)$ \\
\hline
\end{tabular}

tEORTC QLQ-C15-PAL: all items have scores ranging from 0 to 100. A higher score on global health status, the emotional functioning scale or physical functioning scale indicates a higher level of global health or better functioning. Inversely, a higher score on a symptom indicates more severe symptoms or problems. 
Table 2: Satisfaction of patients with advanced cancer with hospital care (EORTC INPATSAT-32) and factor loadings for the INPATSAT-32 subscales

\begin{tabular}{|c|c|c|c|c|}
\hline \multirow{3}{*}{ INPATSAT-32 subscales } & \multirow{2}{*}{$\begin{array}{c}\text { Total } \\
\mathrm{n}=105\end{array}$} & \multicolumn{3}{|c|}{ Factor Loadings ${ }^{\dagger}$} \\
\hline & & $\begin{array}{l}\text { Eigenvalue } \\
(\Lambda) 8.931\end{array}$ & $\begin{array}{l}\text { Eigenvalue } \\
(\Lambda) 1.282\end{array}$ & $\begin{array}{l}\text { Eigenvalue } \\
(\Lambda) 1.031\end{array}$ \\
\hline & Mean (sd) & Factor 1 & Factor 2 & Factor 3 \\
\hline \multicolumn{5}{|l|}{ Satisfaction with physicians’ł } \\
\hline Technical skills & $68(22)$ & & 0.972 & \\
\hline Interpersonal skills & $67(24)$ & & 0.953 & \\
\hline Information & $66(24)$ & & 0.818 & \\
\hline Availability & $62(22)$ & & 0.747 & \\
\hline \multicolumn{5}{|l|}{ Satisfaction with nurses' } \\
\hline Technical skills & $72(21)$ & 0.877 & & \\
\hline Interpersonal skills & $71(23)$ & 1.021 & & \\
\hline Information & $67(24)$ & 0.829 & & \\
\hline Availability & $64(25)$ & 0.799 & & \\
\hline Exchange of information & $62(20)$ & 0.403 & & \\
\hline $\begin{array}{l}\text { Other hospital personnel } \\
\text { Kindness and helpfulness }\end{array}$ & $60(21)$ & & & 0.568 \\
\hline Waiting time & $61(21)$ & & & \\
\hline Access (parking, means of transport,...) & $59(22)$ & & & 0.853 \\
\hline Comfort /cleanness & $62(25)$ & & & 0.743 \\
\hline General satisfaction & $72(21)$ & 0.424 & & 0.430 \\
\hline
\end{tabular}

†Extraction method: Principal Axis Factoring and Oblimin rotation Factor loadings under 0.40 are not shown.

\#EORTC INPATSAT-32: all items are scored from 0 to 100 where a higher score indicates a higher level of satisfaction. 
Table 3: The association between patient demographics, disease characteristics, quality of life (EORTC QLQ-C15-PAL) and general satisfaction (EORTC INPATSAT-32)

\begin{tabular}{|c|c|c|c|c|c|c|}
\hline & \multicolumn{6}{|c|}{ General satisfaction IN-PATSAT 32† } \\
\hline & \multicolumn{3}{|c|}{ Univariate linear regression } & \multicolumn{3}{|c|}{ Multivariable regression $\ddagger$} \\
\hline & B & $\mathrm{Cl}$ & $p$ value & B & $\mathrm{Cl}$ & $p$ value \\
\hline Gender (male vs. female) & -3.89 & $-12.13-4.34$ & 0.35 & & & \\
\hline Age at admission & 0.24 & $-0.16-0.65$ & 0.24 & -0.05 & $-0.48-0.37$ & 0.81 \\
\hline Marital status (single /unmarried vs. married) & 3.19 & $-5.33-11.71$ & 0.46 & & & \\
\hline Place of residence (other vs. home) & -10.18 & $-31.34-10.97$ & 0.34 & & & \\
\hline $\begin{array}{l}\text { Discharge destination (Home = reference) } \\
\text { Nursing home / care home / hospice } \\
\text { Other }\end{array}$ & $\begin{array}{l}-1.35 \\
-2.19\end{array}$ & $\begin{array}{l}-14.27-11.57 \\
-21.43-17.05\end{array}$ & $\begin{array}{l}0.96 \\
0.84 \\
0.82\end{array}$ & & & \\
\hline Duration of current hospital admission§ & 0.21 & $-0.35-0.76$ & 0.47 & & & \\
\hline $\begin{array}{l}\text { Diagnosis (Gastro-intestinal cancer }=\text { reference) } \\
\text { Urogenital cancer } \\
\text { Breast cancer } \\
\text { Lung cancer } \\
\text { Other }\end{array}$ & $\begin{array}{r}1.19 \\
9.77 \\
3.10 \\
-0.24\end{array}$ & $\begin{array}{l}-10.01-12.40 \\
2.85-22.37 \\
-9.52-15.71 \\
-15.00-14.51 \\
\end{array}$ & $\begin{array}{l}0.63 \\
0.83 \\
0.13 \\
0.63 \\
0.98 \\
\end{array}$ & & & \\
\hline $\begin{array}{l}\text { Treatment status (Patient received anti-tumor therapy }= \\
\text { reference) } \\
\text { No options for anti-tumor therapy left } \\
\text { Other }\end{array}$ & $\begin{array}{l}-1.24 \\
-0.93\end{array}$ & $\begin{array}{c}-10.89-8.41 \\
-12.53-10.67\end{array}$ & $\begin{array}{l}0.97 \\
0.80 \\
0.87\end{array}$ & & & \\
\hline $\begin{array}{l}\text { Comorbidity } \\
\text { No comorbidity } \\
1 \text { comorbidity } \\
>1 \text { comorbidity }\end{array}$ & 4.11 & $-0.97-9.19$ & 0.11 & 4.30 & $-1.13-9.73$ & 0.12 \\
\hline Hospital admission was (planned vs. unplanned) & -6.59 & $-18.17-4.99$ & 0.26 & -12.54 & $-25.04-0.04$ & 0.05 \\
\hline $\begin{array}{l}\text { WHO performance status. The patient is.... } \\
\text { (1) Able to carry out all normal activity without } \\
\text { restrictions } \\
\text { (2) Restricted in physically strenuous activity but }\end{array}$ & & & & & & \\
\hline
\end{tabular}




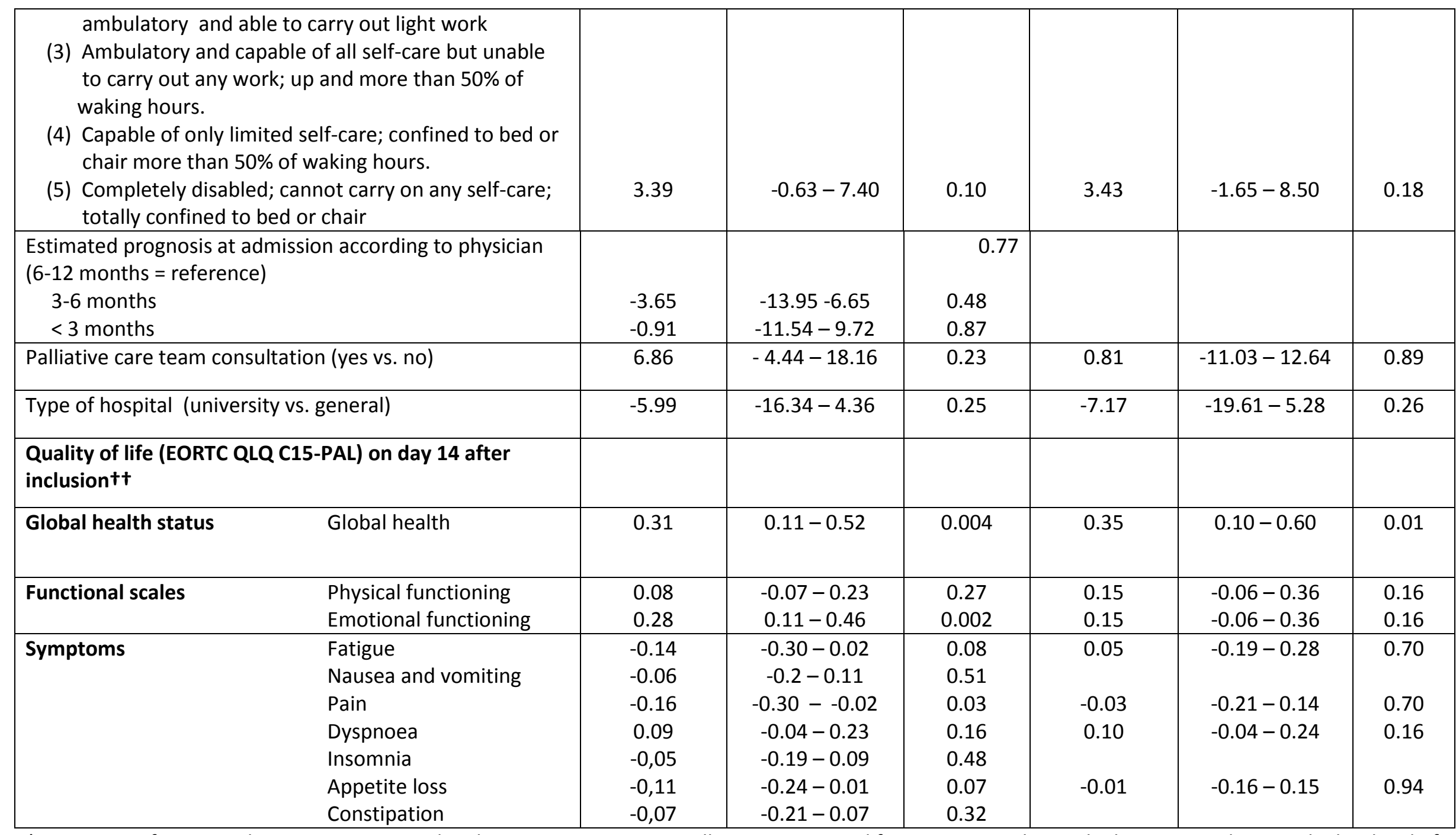

†Patient satisfaction with care was measured with EORTC INPATSAT-32: all items are scored from 0 to 100 where a higher score indicates a higher level of satisfaction.

$\ddagger$ Variables with $\mathrm{P}<0,30$ were included in the multivariable model. 
- $F=2.61, p=0.005, R$ Squared $=0.32$ (Adjusted $R$ Squared $=0.20$ )

$\S$ Linear regression was done as for continuous variables in order to show a possible tendency.

IlLinear regression was done as for ordinal variables in order to show a possible tendency.

†+Quality of life was measured with the EORTC QLQ-C15-PAL: all items have scores from 0 to 100 . A higher score on global health status, the emotional functioning scale or physical functioning scale indicates a higher level of global health or better functioning. Inversely, a higher score on a symptom indicates more severe symptoms or problems. 
Table 4: The association between patient demographics, disease characteristics, quality of life (EORTC QLQ-C15-PAL) and satisfaction with nurses and exchange of information

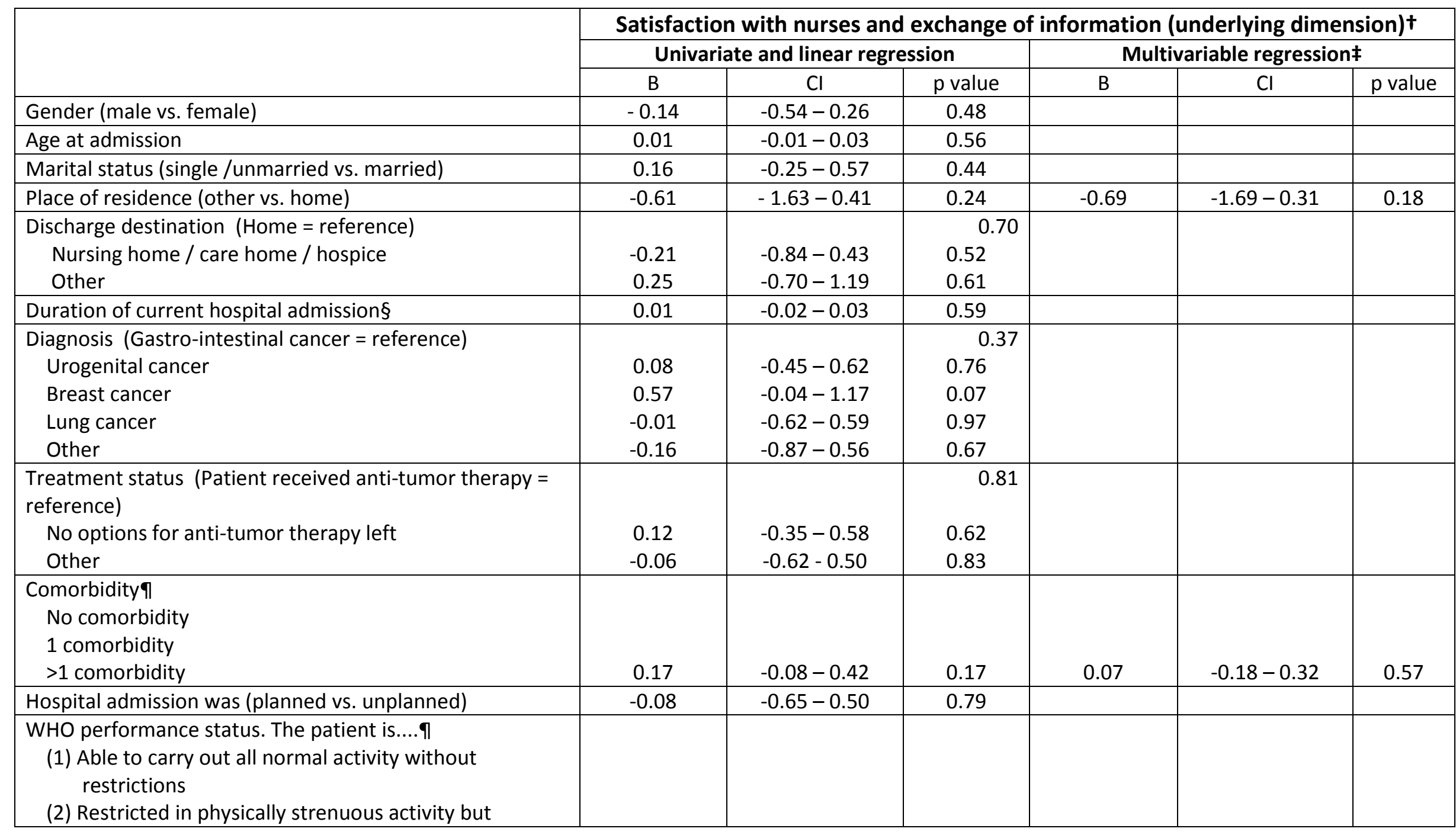




\begin{tabular}{|c|c|c|c|c|c|c|c|}
\hline \multicolumn{2}{|c|}{$\begin{array}{l}\text { ambulatory and able to carry out light work } \\
\text { (3) Ambulatory and capable of all self-care but unable } \\
\text { to carry out any work; up and more than } 50 \% \text { of } \\
\text { waking hours. } \\
\text { (4) Capable of only limited self-care; confined to bed } \\
\text { or chair more than } 50 \% \text { of waking hours. } \\
\text { (5) Completely disabled; cannot carry on any self- } \\
\text { care; totally confined to bed or chair }\end{array}$} & 0.10 & $-0.10-0.30$ & 0.32 & & & \\
\hline \multicolumn{2}{|c|}{$\begin{array}{l}\text { Estimated prognosis at admission according to physician } \\
\text { (6-12 months = reference) } \\
3-6 \text { months } \\
<3 \text { months }\end{array}$} & $\begin{array}{l}-0.11 \\
0.06\end{array}$ & $\begin{array}{l}-0.61-0.38 \\
-0.45-0.57\end{array}$ & $\begin{array}{l}0.78 \\
0.65 \\
0.81\end{array}$ & & & \\
\hline \multicolumn{2}{|c|}{ Palliative care team consultation (yes vs. no) } & 0.36 & $-0.19-0.91$ & 0.20 & 0.50 & $-0.09-1.09$ & 0.10 \\
\hline \multicolumn{2}{|c|}{ Type of hospital (university vs. general) } & -0.16 & $-0.66-0.35$ & 0.54 & & & \\
\hline \multicolumn{8}{|c|}{$\begin{array}{l}\text { Quality of life (EORTC QLQ C15-PAL) on day } 14 \text { after } \\
\text { inclusiontt }\end{array}$} \\
\hline Symptoms & $\begin{array}{l}\text { Fatigue } \\
\text { Nausea and vomiting } \\
\text { Pain } \\
\text { Dyspnoea } \\
\text { Insomnia } \\
\text { Appetite loss } \\
\text { Constipation } \\
\end{array}$ & $\begin{array}{c}-0.002 \\
-0.001 \\
-0.005 \\
0.001 \\
0.001 \\
-0.003 \\
-0.004 \\
\end{array}$ & $\begin{array}{l}-0.010-0.005 \\
-0.009-0.007 \\
-0.012-0.002 \\
-0.005-0.008 \\
-0.006-0.008 \\
-0.009-0.003 \\
-0.011-0.003\end{array}$ & $\begin{array}{l}0.54 \\
0.81 \\
0.13 \\
0.70 \\
0.71 \\
0.32 \\
0.29\end{array}$ & -0.004 & $-0.011-0.003$ & 0.85 \\
\hline
\end{tabular}

†Patient satisfaction with care was measured with EORTC INPATSAT-32: all items are scored from 0 to 100 where a higher score indicates a higher level of satisfaction.

$\ddagger$ Variables with $P<0,30$ were included in the multivariable model. 
- $\quad F=1.72, p=0.11, R$ Squared $=0.12$ (Adjusted R Squared $=0.05$ )

$\S$ Linear regression was done as for continuous variables in order to show a possible tendency.

ILinear regression was done as for ordinal variables in order to show a possible tendency.

†+Quality of life was measured with the EORTC QLQ-C15-PAL: all items have scores from 0 to 100 . A higher score on global health status, the emotional functioning scale or physical functioning scale indicates a higher level of global health or better functioning. Inversely, a higher score on a symptom indicates more severe symptoms or problems. 
Table 5: The association between patient demographics, disease characteristics, quality of life (EORTC QLQ-C15-PAL) and satisfaction with physicians

\begin{tabular}{|c|c|c|c|c|c|c|}
\hline & \multicolumn{6}{|c|}{ Satisfaction with physicians (underlying dimension)t } \\
\hline & \multicolumn{3}{|c|}{ Univariate and linear regression } & \multicolumn{3}{|c|}{ Multivariable regression $\ddagger$} \\
\hline & B & $\mathrm{Cl}$ & $p$ value & B & $\mathrm{Cl}$ & $p$ value \\
\hline Gender (male vs female) & -0.01 & $-0.41-0.39$ & 0.96 & & & \\
\hline Age at admission & 0.01 & $-0.01-0.03$ & 0.13 & 0.02 & $-0.00-0.04$ & 0.08 \\
\hline Marital status (single /unmarried vs. married) & 0.15 & $-0.27-0.56$ & 0.49 & & & \\
\hline Place of residence (other vs.home) & 0.31 & $-0.74-1.36$ & 0.56 & & & \\
\hline $\begin{array}{l}\text { Discharge destination (Home = reference) } \\
\text { Nursing home / care home / hospice } \\
\text { Other }\end{array}$ & $\begin{array}{c}-0.11 \\
0.15\end{array}$ & $\begin{array}{l}-0.74-0.52 \\
-0.79-1.09\end{array}$ & $\begin{array}{l}0.89 \\
0.74 \\
0.76\end{array}$ & & & \\
\hline Duration of current hospital admission§ & -0.01 & $-0.03-0.02$ & 0.61 & & & \\
\hline $\begin{array}{l}\text { Diagnosis (Gastro-intestinal cancer }=\text { reference) } \\
\text { Urogenital cancer } \\
\text { Breast cancer } \\
\text { Lung cancer } \\
\text { Other }\end{array}$ & $\begin{array}{l}0.08 \\
0.53 \\
-0.26 \\
-0.10\end{array}$ & $\begin{array}{l}-0.46-0.62 \\
-0.08-1.13 \\
-0.87-0.34 \\
-0.81-0.61\end{array}$ & $\begin{array}{l}0.29 \\
0.76 \\
0.09 \\
0.39 \\
0.77\end{array}$ & $\begin{array}{r}0.25 \\
1.06 \\
-0.00 \\
-0.01\end{array}$ & $\begin{array}{r}-0.29-0.80 \\
0.40-1.72 \\
-0.62-0.62 \\
-0.75-0.74\end{array}$ & $\begin{array}{l}0.03 \\
0.36 \\
0.00 \\
0.99 \\
0.99\end{array}$ \\
\hline $\begin{array}{l}\text { Treatment status (Patient received anti-tumor therapy }= \\
\text { reference) } \\
\text { No options for anti-tumor therapy left } \\
\text { Other }\end{array}$ & $\begin{array}{l}-0.01 \\
0.14 \\
\end{array}$ & $\begin{array}{r}-0.46-0.43 \\
-0.41-0.68\end{array}$ & $\begin{array}{r}0.86 \\
0.95 \\
0.62\end{array}$ & & & \\
\hline $\begin{array}{l}\text { Comorbidity } 9 \\
\text { No comorbidity } \\
1 \text { comorbidity } \\
>1 \text { comorbidity }\end{array}$ & 0.27 & $0.03-0.51$ & 0.03 & 0.21 & $-0.05-0.47$ & 0.11 \\
\hline Hospital admission was (planned vs. unplanned) & 0.19 & $-0.38-0.77$ & 0.51 & & & \\
\hline $\begin{array}{l}\text { WHO performance status. The patient is.... } \\
\text { (1) Able to carry out all normal activity without } \\
\text { restrictions } \\
\text { (2) Restricted in physically strenuous activity but } \\
\text { ambulatory and able to carry out light work }\end{array}$ & & & & & & \\
\hline
\end{tabular}




\begin{tabular}{|c|c|c|c|c|c|c|c|}
\hline \multicolumn{2}{|c|}{$\begin{array}{l}\text { (3) Ambulatory and capable of all self-care but } \\
\text { unable to carry out any work; up and more than } \\
50 \% \text { of waking hours. } \\
\text { (4) Capable of only limited self-care; confined to bed } \\
\text { or chair more than } 50 \% \text { of waking hours. } \\
\text { (5) Completely disabled; cannot carry on any self- } \\
\text { care; totally confined to bed or chair }\end{array}$} & 0.03 & $-0.17-0.23$ & 0.79 & & & \\
\hline \multicolumn{2}{|c|}{$\begin{array}{l}\text { Estimated prognosis at admission according to physician } \\
\text { (6-12 months = reference) } \\
\text { 3-6 months } \\
<3 \text { months }\end{array}$} & $\begin{array}{l}-0.25 \\
-0.12\end{array}$ & $\begin{array}{l}-0.72-0.23 \\
-0.62-0.38\end{array}$ & $\begin{array}{r}0.59 \\
0.31 \\
0.63\end{array}$ & & & \\
\hline \multicolumn{2}{|c|}{ Palliative care team consultation (yes vs.no) } & 0.12 & $-0.44-0.67$ & 0.68 & & & \\
\hline \multicolumn{2}{|c|}{ Type of hospital (university vs. general) } & 0.29 & $-0.21-0.80$ & 0.26 & 0.40 & $-0.20-1.00$ & 0.19 \\
\hline \multicolumn{8}{|c|}{$\begin{array}{l}\text { Quality of life (EORTC QLQ-C15-PAL) on day } 14 \text { after } \\
\text { inclusiontt }\end{array}$} \\
\hline
\end{tabular}

†Patient satisfaction with care was measured with EORTC INPATSAT-32: all items are scored from 0 to 100 where a higher score indicates a higher level of satisfaction.

$¥$ Variables with $\mathrm{P}<0,30$ were included in the multivariable model.

- $F=2.04, p=0.03, R$ Squared $=0.28($ Adjusted $R$ Squared $=0.14)$ 
FLinear regression was done as for continuous variables in order to show a possible tendency.

ILinear regression was done as for ordinal variables in order to show a possible tendency.

+†Quality of life was measured with the EORTC QLQ-C15-PAL: all items have scores from 0 to 100. A higher score on global health status, the emotional functioning scale or physical functioning scale indicates a higher level of global health or better functioning. Inversely, a higher score on a symptom indicates more severe symptoms or problems. 
Table 6: The association between patient demographics, disease characteristics, quality of life (EORTC QLQ-C15-PAL) and satisfaction with hospital services

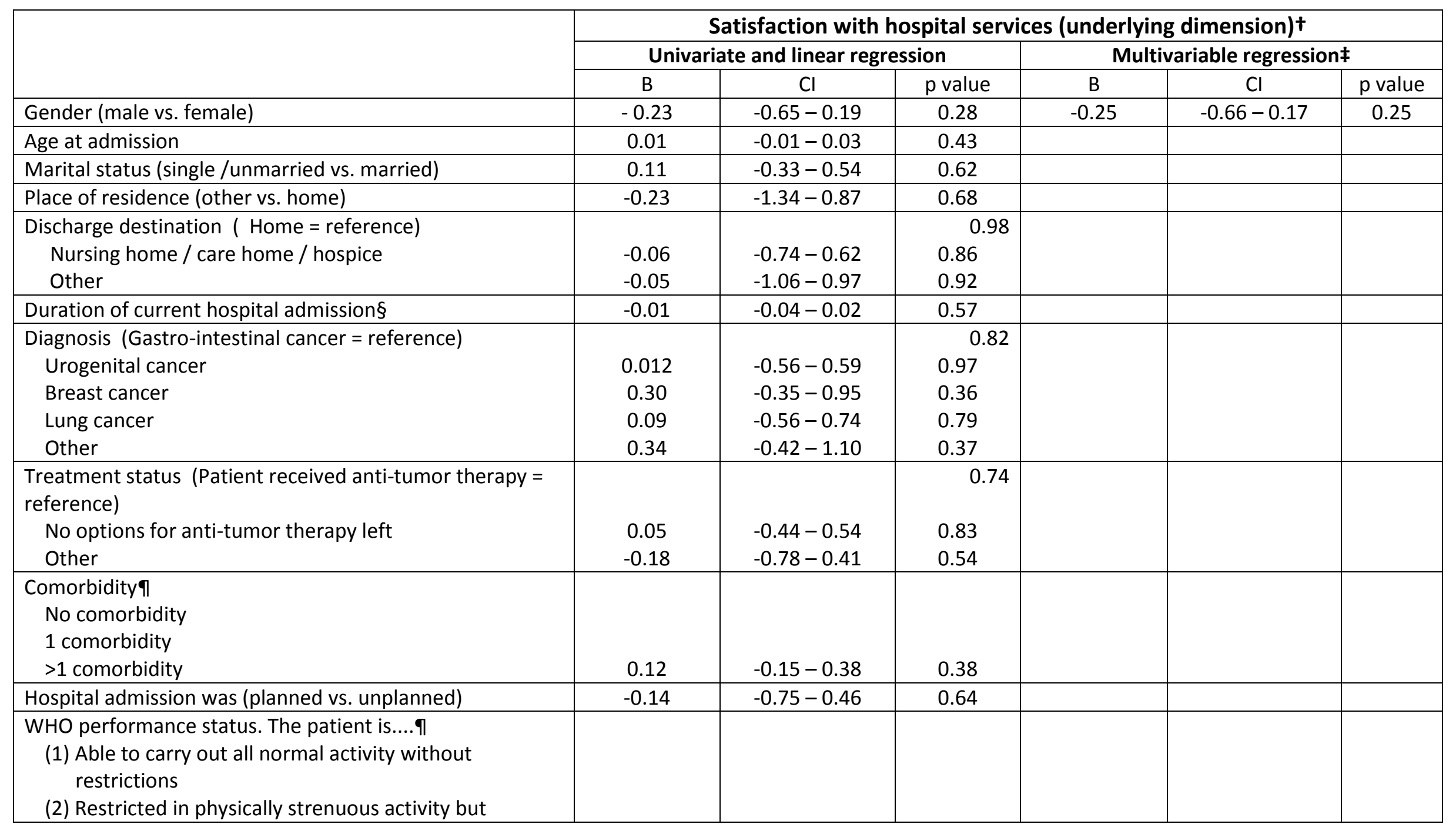




\begin{tabular}{|c|c|c|c|c|c|c|c|}
\hline \multicolumn{2}{|c|}{$\begin{array}{l}\text { ambulatory and able to carry out light work } \\
\text { (3) Ambulatory and capable of all self-care but } \\
\text { unable to carry out any work; up and more than } \\
50 \% \text { of waking hours. } \\
\text { (4) Capable of only limited self-care; confined to bed } \\
\text { or chair more than } 50 \% \text { of waking hours. } \\
\text { (5) Completely disabled; cannot carry on any self- } \\
\text { care; totally confined to bed or chair }\end{array}$} & 0.22 & $0.02-0.43$ & 0.03 & 0.17 & $-0.03-0.37$ & 0.10 \\
\hline \multicolumn{2}{|c|}{$\begin{array}{l}\text { Estimated prognosis at admission according to physician } \\
(6-12 \text { months = reference) } \\
3-6 \text { months } \\
<3 \text { months }\end{array}$} & $\begin{array}{l}-0.31 \\
-0.08\end{array}$ & $\begin{array}{l}-0.83-0.21 \\
-0.63-0.46\end{array}$ & $\begin{array}{l}0.48 \\
0.24 \\
0.76\end{array}$ & & & \\
\hline \multicolumn{2}{|c|}{ Palliative care team consultation (yes vs. no ) } & 0.36 & $-0.22-0.94$ & 0.22 & 0.11 & $-0.47-0.69$ & 0.71 \\
\hline \multicolumn{2}{|c|}{ Type of hospital (university vs. general) } & -0.57 & $-1.10--0.05$ & 0.03 & -0.38 & $-0.92-0.16$ & 0.17 \\
\hline \multicolumn{8}{|c|}{$\begin{array}{l}\text { Quality of life (EORTC QLQ-C15-PAL) on day } 14 \text { after } \\
\text { inclusiont+ }\end{array}$} \\
\hline Global health status & Global health & 0.013 & $0.003-0.024$ & 0.02 & 0.006 & $-0.006-0.019$ & 0.34 \\
\hline Functional scales & $\begin{array}{l}\text { Physical functioning } \\
\text { Emotional functioning }\end{array}$ & $\begin{array}{l}0.001 \\
0.019 \\
\end{array}$ & $\begin{array}{c}-0.007-0.009 \\
0.010-0.028\end{array}$ & $\begin{array}{c}0.81 \\
0,000\end{array}$ & 0.016 & $0.006-0.027$ & 0.002 \\
\hline Symptoms & $\begin{array}{l}\text { Fatigue } \\
\text { Nausea and vomiting } \\
\text { Pain } \\
\text { Dyspnoea } \\
\text { Insomnia } \\
\text { Appetite loss } \\
\text { Constipation }\end{array}$ & $\begin{array}{c}-0.007 \\
-0.009 \\
-0.009 \\
0.005 \\
-0.001 \\
-0.005 \\
-0.001 \\
\end{array}$ & $\begin{array}{l}-0.015-0.001 \\
-0.017-0.000 \\
-0.016--0.002 \\
-0.002-0.012 \\
-0.008-0.006 \\
-0.012-0.001 \\
-0.009-0.006\end{array}$ & $\begin{array}{l}0.08 \\
0.04 \\
0.01 \\
0.15 \\
0.73 \\
0.11 \\
0.69\end{array}$ & $\begin{array}{r}0.001 \\
-0.002 \\
-0.004 \\
0.007\end{array}$ & $\begin{array}{c}-0.009-0.011 \\
-0.011-0.007 \\
-0.012-0.004 \\
0.001-0.014 \\
-0.006-0.008\end{array}$ & $\begin{array}{l}0.88 \\
0.69 \\
0.33 \\
0.03\end{array}$ \\
\hline
\end{tabular}

†Patient satisfaction with care was measured with EORTC INPATSAT-32: all items are scored from 0 to 100 where a higher score indicates a higher level of satisfaction.

Variables with $\mathrm{P}<0,30$ were included in the multivariable model. 
- $\quad F=3.46, p=0.001, R$ Squared $=0.31$ (Adjusted $R$ Squared $=0.22$ )

$\S$ Linear regression was done as for continuous variables in order to show a possible tendency.

ILinear regression was done as for ordinal variables in order to show a possible tendency.

†+Quality of life was measured with the EORTC QLQ-C15 PAL: all items have scores from 0 to 100 . A higher score on global health status, the emotional functioning scale or physical functioning scale indicates a higher level of global health or better functioning. Inversely, a higher score on a symptom indicates more severe symptoms or problems. 